\title{
BALANÇO SOCIAL: IDENTIFICAÇÃO DE INDICADORES SOCIOECONÔMICOS E AMBIENTAIS DE EMPRESAS COM CERTIFICAÇÃO DE RESPONSABILIDADE SOCIAL EM MATO GROSSO
}

\author{
Rafaella Manhani Ponçoni ${ }^{1}$ \\ Cleiton Franco ${ }^{2}$
}

\begin{abstract}
RESUMO
A pesquisa buscou identificar indicadores internos e externos de balanços sociais divulgados por empresas que receberam o Certificado de Responsabilidade Social de Mato Grosso nas edições de 2011 e 2012, além de verificar a forma de publicação dos relatórios e traçar um perfil dessas organizações. A metodologia utilizada foi descritiva com abordagem quantitativa através da análise documental dos balanços sociais disponíveis no site da Assembléia Legislativa do Estado de Mato Grosso. O estudo mostrou que existe um modelo padrão de divulgação dos balanços que não contempla a demonstração do valor adicionado (DVA) e que houve menor participação referente a empresas de pequeno porte. Concluiu-se que a distribuição da riqueza gerada pelas empresas não foi utilizada como critério para concessão do Certificado de Responsabilidade Social. Além disso, não houve padronização dos balanços divulgados, o que dificultou a comparabilidade dos dados.
\end{abstract}

Palavras-chave: Demonstração do Valor Adicionado. Categorias. Setores. Empregabilidade.

\section{INTRODUÇÃO}

Durante séculos, as demonstrações contábeis foram direcionadas unicamente para uso dos proprietários, posteriormente, transformaram-se em informações externas para investidores, credores, fisco e outras entidades interessadas no patrimônio das organizações. De acordo com Tinoco e Kraemer (2004), a partir dos anos 60 nos Estados Unidos da América e na década de 70 na Europa, particularmente na França, a sociedade passou a cobrar maior responsabilidade social das empresas, em consequência disso o uso das demonstrações expandiu-se para fins sociais.

Exige-se cada vez mais que as empresas contribuam com o desenvolvimento econômico sustentável. Sua aceitabilidade, no mercado, tem sido gradativamente, condicionada à demonstração de sua contribuição com a sociedade e meio ambiente em geral e o tema vem despertando interesse de administradores dos mais variados ramos. Todos os anos empresas publicam balanços sociais com o objetivo de divulgar as ações promovidas.

A Assembleia Legislativa de Mato Grosso, através da Lei 7.687/02 (MATO

\footnotetext{
${ }^{1}$ UNEMAT
}

${ }^{2}$ UNEMAT 
GROSSO, 2002), criou o Certificado de Responsabilidade Social de Mato Grosso, de autoria dos deputados José Riva, Humberto Bosaipo e Eliene Lima, com o intuito de promover o reconhecimento público de instituições, empresas, órgãos públicos e Organizações Sociais de Interesse Público (OSCIPs) que publicam seus balanços.

Existem diversos trabalhos relacionados à balanços sociais e responsabilidade social das empresas publicados no Brasil. Alberton et al. (2008), por exemplo, analisaram a evidenciação da gestão ambiental nas S/A's brasileiras, ressaltando conceitos, a importância, as normas ambientais e o contador como agente social. Com a pesquisa, verificou-se que a contabilidade apresenta papel importante na responsabilidade social através da elaboração do balanço social, apesar da falta de padronização do relatório.

Carvalho e Siqueira (2005) discorreram acerca da regulamentação brasileira do balanço social, visando identificar as normatizações existentes e realizar uma análise qualitativa das disposições, verificando aspectos como exposição de externalidades, grau de transparência e padronização, instituição de sanções e selos ou certificados. Os autores concluíram que a existência de diferentes estruturas dificultou a comparabilidade de informações.

Machado e Machado (2009) por sua vez, verificaram que a responsabilidade social causava impacto ao desempenho financeiro de 237 empresas, pertencentes a 15 setores da economia, num período de cinco anos. A amostra era constituída por empresas que tinham seus balanços sociais disponíveis no banco de dados do Instituto Brasileiro de Análises Sociais e Econômicas (IBASE) e constavam entre as 500 maiores e melhores empresas, segundo a publicação anual da Revista Exame, entre 2003 e 2007.

Já Macedo, Sousa e Sousa (2008), traçaram análise comparativa do desempenho contábil-financeiro de empresas socialmente responsáveis através de indicadores como liquidez, endividamento e lucratividade, referentes ao ano de 2006 e observou que não existiam diferenças significativas nos índices entre as empresas comparadas, refutando a ideia de que empresas com posturas "politicamente" corretas apresentam melhor desempenho.

Bertagnolli, Ott e Damacena (2005) também estudaram a influência dos investimentos sociais e ambientais no desempenho econômico das empresas. Para tal, utilizaram balanços sociais de 176 empresas publicados no site do Instituto Brasileiro de Análises Sociais e Econômicas. Concluíram, ao contrário dos outros dois artigos 
publicados, que a receita líquida e o resultado operacional estavam associados aos investimentos internos e externos das empresas pesquisadas, com destaque especial aos benefícios oferecidos aos funcionários.

Pinto e Ribeiro (2004) revisaram os conceitos e indicadores dos balanços sociais divulgados pelas maiores indústrias de Santa Catarina, levando-se em conta a quantidade de empregados de cada uma delas para enquadramento quanto ao tamanho. A pesquisa mostrou que o balanço social vem sendo difundido entre as empresas estudadas, porém em modelos diferentes, com indicadores variados e ausência de informações relevantes.

David (2003) em seu trabalho identificou as informações que as empresas disponibilizaram com base nos balanços sociais de 88 (oitenta e oito) empresas de pequeno, médio e grande porte, relativos ao ano 2000 e encaminhados à Assembleia Legislativa do estado do Rio Grande do Sul no ano de 2001 para concorrer ao Prêmio de Responsabilidade Social. Ele constatou que houve maior participação de empresas de grande porte e que o público interno recebeu a maior parte dos investimentos.

Baggentoss e Donadone (2009) por sua vez, buscaram compreender o processo de difusão da responsabilidade social com enfoque no Certificado de Responsabilidade Social de Mato Grosso. Verificaram que os modelos de balanços disponibilizados omitiam itens constantes nos modelos originais, provindos do IBASE, mas cumpriam a função de promover as entidades socialmente responsáveis e causar a difusão dos conceitos, benefícios e ações no estado.

Diante dos trabalhos já publicados e da necessidade de aprofundar o tema, o presente estudo buscou identificar os indicadores internos e externos dos balanços sociais divulgados pelas empresas que receberam o Certificado de Responsabilidade Social de Mato Grosso nas edições de 2011 e 2012. A análise foi necessária para alcançar objetivos específicos tais como identificar o perfil das empresas certificadas no período, bem como verificar a padronização dos balanços divulgados, buscando respostas as seguintes questões:

- Existe um modelo padrão para divulgação dos balanços das empresas que concorrem à certificação? Ele contempla a Demonstração de Valor Adicionado (DVA)?

- Quais os critérios utilizados pela Assembleia Legislativa de Mato Grosso para conceder o Certificado de Responsabilidade Social?

- Quais categorias e setores tiveram maior participação no evento? 
- Houve evolução no número de empregos gerados?

- Qual o investimento realizado pelas empresas em cada ambiente?

- Qual ambiente foi priorizado pela maioria das entidades?

- Qual a relação entre a Receita Líquida e os investimentos realizados?

\section{REFERENCIAL TEÓRICO}

\subsection{Responsabilidade Social e Balanço Social}

Responsabilidade Social, para Tinoco e Kraemer (2004), é entender a empresa como um organismo social complexo, resultado da colisão de interesses de diferentes grupos, com valor agregado, tais como fornecedores, emprestadores, empregados, acionistas, clientes, Estado, sindicato, comunidade. Além do lucro, a Responsabilidade Social remete à gestão de empresas, mecanismos de controle social que possam atender as necessidades humanas, ambientais, produzindo serviços de qualidade de forma confiável, acessível e segura.

Já para o Instituto Ethos (2001), a responsabilidade social das empresas tem como principal característica a coerência ética nas práticas e relações com seus diversos públicos, contribuindo para o desenvolvimento contínuo das pessoas, das comunidades e dos relacionamentos entre si e o meio ambiente. Ao adicionar às suas competências básicas a conduta ética e socialmente responsável, as empresas conquistam o respeito das pessoas e das comunidades atingidas por suas atividades, o engajamento de seus colaboradores e a preferência dos consumidores.

A responsabilidade social empresarial é considerada um comprometimento da empresa para com a sociedade, envolvendo atividades estratégicas para realização dos negócios, visando, desde a satisfação dos funcionários até o bem-estar da sociedade. Enfim, a Responsabilidade Social pode ser vista como uma forma de conduzir os negócios da empresa de tal forma a torná-la responsável pelo desenvolvimento social. A empresa socialmente responsável é aquela que possui a capacidade de ouvir os interesses das diferentes partes e conseguir incorporá-los no planejamento de suas atividades, procurando atender às demandas de todos e não apenas dos acionistas ou proprietários.

Já o Balanço Social, de acordo com o Instituto Brasileiro de Análises Sociais e Econômicas (IBASE), é um demonstrativo publicado anualmente pela empresa reunindo o conjunto de informações sobre os projetos, benefícios e ações sociais dirigidas aos 
empregados, investidores, analistas de mercado, acionistas e à comunidade. É também um instrumento estratégico para avaliar e multiplicar o exercício da responsabilidade social corporativa.

Tinoco e Kraemer (2004) definem Balanço Social como sendo um instrumento de gestão e de informação que visa a reportar, da forma mais transparente possível, informações econômicas e sociais do desempenho das entidades, aos mais diferentes usuários. De acordo com os autores, no balanço social a empresa mostra o que faz por seus profissionais, dependentes, colaboradores e comunidade, dando transparência às atividades que buscam melhorar a qualidade de vida para todos. Ou seja, sua principal função é tornar pública a responsabilidade social empresarial, construindo maiores vínculos entre a empresa, a sociedade e o meio ambiente.

Santos, Freire e Malo (2007) definem Balanço social como o conjunto de informações que pode ou não ter origem na contabilidade financeira e tem como principal objetivo demonstrar o grau de envolvimento da empresa em relação à sociedade que a acolhe, devendo se entendido como grande instrumento no processo de reflexão sobre as atividades das empresas e dos indivíduos no contexto da comunidade como um todo.

\subsection{Demonstração do Valor Adicionado e Indicadores Socioeconômicos e Ambientais}

De acordo com a Lei 11.638/07, é obrigatória a elaboração da Demonstração do Valor Adicionado (DVA) por Companhias Abertas (S/A). Sua importância é inquestionável segundo Santos, Freire e Malo (2007), pois auxilia no cálculo do produto interno bruto (PIB) e de indicadores sociais extremamente importantes. As decisões de investimentos por áreas, regiões, estados, etc. têm nessa demonstração um instrumento para auxiliar na solução de conflitos.

A DVA é dividida em duas partes: formação da riqueza e distribuição da riqueza, conforme aponta Ricarte (2005). O valor adicionado é calculado subtraindo-se a receita operacional dos recursos adquiridos de terceiros (matéria-prima, mercadorias, embalagens, energia elétrica, etc.) utilizados no processo operacional. Esse primeiro resultado chama-se valor adicionado bruto. Em seguida, considerando-se a depreciação e a consequente redução da riqueza gerada, obtêm-se o valor adicionado líquido. Esse valor corresponde à riqueza gerada pela entidade. 
Com relação à distribuição do valor adicionado, conforme destaca Marion (2005), após a obtenção dos valores é feita a divisão da "fatia do bolo" conforme análise de priorização dos setores ou políticas da empresa.

A DVA pode ser considerada uma demonstração acessória e necessária à análise dos indicadores do Balanço Social, que segundo Silva (2004), são expressões quantitativas que representam uma informação gerada a partir de mensuração e avaliação, com o intuito de controlar ou melhorar a evolução e o desempenho dos negócios, a qualidade dos serviços e produtos, assim como a participação e motivação dos colaboradores.

Podem ser obtidos indicadores de caráter econômico e de caráter social, tais como: valor adicionado por trabalhador; relação entre salários pagos; contribuição para o Produto Interno Bruto; produtividade social da empresa; carga tributária; evolução do emprego; participação e evolução do pessoal por sexo e instrução; classificação do pessoal por faixa etária, classificação do pessoal por antiguidade na empresa; rotatividade; políticas de higiene e segurança no trabalho; níveis de poluição; entre outros.

\subsection{Certificado de Responsabilidade Social de Mato Grosso}

A Assembleia Legislativa de Mato Grosso, através da Lei 7.687/02 (MATO GROSSO, 2002), criou o Certificado de Responsabilidade Social de Mato Grosso, de autoria dos deputados José Riva, Humberto Bosaipo e Eliene Lima, com o intuito de promover o reconhecimento público de instituições, empresas, órgãos públicos e Organizações Sociais de Interesse Público - OSCIPs.

Conforme destacam Baggentoss e Donadone (2009), este tipo de evento não é único no país e há projetos de abrangência nacional tramitando no congresso que visam transformar a responsabilidade social em lei. Ainda de acordo com os autores, a primeira lei de abrangência estadual efetivada foi no Rio Grande do Sul, com a aprovação da Lei 11.440/00 que criou e regulamentou a lei intitulada Certificado de Responsabilidade Social. O Certificado de Responsabilidade de Mato Grosso caracterizou-se como uma segunda manifestação e possui basicamente os mesmos preceitos da primeira.

A Assembleia Legislativa do Estado de Mato Grosso difunde a responsabilidade social através do Balanço Social, premiando a participação de empresas que apresentarem os dados em determinado período, sendo que compete à Comissão Mista, composta por representantes de entidades da sociedade civil organizada, planejar o evento anual e 
deliberar sobre os critérios que nortearão a escolha das empresas, órgãos públicos e demais entidades a serem agraciadas com o Certificado de Responsabilidade Social e o Troféu Responsabilidade Social - Destaque MT.

Uma das premissas é se enquadrar em uma das seis categorias apresentadas no edital para fazer uso do modelo de Balanço Social disponibilizado a cada uma delas: micro e pequenas empresas (modelo 1), médio e grande porte (modelo 2), organizações do terceiro setor (modelo 3), instituições de ensino e fundações privadas (modelo 4), órgãos públicos (modelo 5) e empresas públicas e sociedades de economia mista (modelo $6)$.

Os demais critérios se restringem a aceitar somente balanços preenchidos na íntegra e exigir declaração de que a organização não utiliza mão-de-obra infantil, trabalho degradante análogo à escravidão, não tenha envolvimento com prostituição ou exploração sexual infantil e não esteja envolvida em corrupção.

A primeira edição do evento ocorreu em 2006 e contou com a participação de 5 empresas. Na última edição em 2012, já somavam mais de 30 participantes.

\section{METODOLOGIA}

Esta pesquisa pode ser classificada como descritiva quanto aos objetivos, uma vez que, segundo GIL (2002), visa descrever as características das entidades e a existência de associações entre variáveis. Quanto à abordagem, enquadra-se como quantitativa na medida em que utiliza dados numéricos e correlaciona os resultados obtidos.

É considerada ainda como pesquisa documental por utilizar como fonte de dados, balanços sociais disponibilizados no site da Assembleia Legislativa de Mato Grosso. A amostra foi intencional e não probabilística e utilizou 79 balanços publicados das edições de 2011 e 2012, já que os relatórios das edições anteriores não estavam disponíveis no site.

De posse dos 79 balanços sociais, o primeiro passo foi verificar se houve padronização dos relatórios divulgados. Em seguida, buscou-se identificar os indicadores comuns a todos os modelos, de forma a permitir a comparabilidade das informações. Essa identificação foi possível após a criação de um ranking de ocorrências. Feito essa identificação, criou-se tabelas e gráficos com os dados obtidos.

As empresas foram separadas quanto à categoria e setor, em seguida foram 
analisados os dados internos e externos referentes às duas edições do evento. Através da segmentação por ambientes foi possível identificar o ambiente que recebeu mais investimentos no período de entre 2009 e 2011.

\section{RESULTADOS}

A Tabela 1 ilustra a distribuição das empresas que concorreram ao Certificado de Responsabilidade Social de Mato Grosso nas edições 2011 e 2012. Apenas 2 empresas concorreram respectivamente nas categorias Autarquia/Fundação Pública e Empresa Pública/Sociedade de Economia Mista. Em 2012 houve uma redução no número de Médias e Grandes Empresas participantes, eram 22 em 2011 e apenas 21 no ano seguinte. As Micro Empresas/Empresas de Pequeno Porte, por sua vez, somavam 3 em 2011 e 4 em 2012, assim como as empresas que concorreram na categoria Terceiro Setor, que eram 12 na edição 2011 e 13 na edição 2012.

Ao contrário de David (2003), que identificou maior participação de empresas de grande porte em seu trabalho, observa-se na Tabela 1 que houve maior participação de Médias e Grandes Empresas em Mato Grosso.

Tabela 1. Distribuição de empresas quanto à categoria

\begin{tabular}{lcccc}
\hline \multicolumn{1}{c}{ Categoria } & $\mathbf{2 0 1 1}$ & $\mathbf{\%}$ & $\mathbf{2 0 1 2}$ & $\mathbf{\%}$ \\
\hline Autarquia/Fundação Pública & 1 & $3 \%$ & 1 & $3 \%$ \\
Empresa Pública/Sociedade de Economia Mista & 1 & $3 \%$ & 1 & $3 \%$ \\
Média e Grande Empresa & 22 & $56 \%$ & 21 & $53 \%$ \\
Micro Empresa/Empresa de Pequeno Porte & 3 & $8 \%$ & 4 & $10 \%$ \\
Terceiro Setor & 12 & $31 \%$ & 13 & $33 \%$ \\
Total de Empresas & $\mathbf{3 9}$ & $100 \%$ & $\mathbf{4 0}$ & $\mathbf{1 0 0 \%}$ \\
\hline
\end{tabular}

Em termos percentuais, as Autarquias/Fundações Públicas corresponderam a 3\%, assim como as Empresas Públicas/Sociedades de Economia Mista em ambas as edições. $\mathrm{Na}$ categoria Média e Grande Empresa, as participantes corresponderam a $56 \%$ em 2011 e 53\% em 2012, enquanto as Micro Empresas/Empresas de Pequeno Porte representavam 8\% em 2011 e 10\% em 2012. O terceiro Setor por sua vez, representou $31 \%$ do total das empresas na edição de 2011 e 33\% em 2012.

A distribuição das empresas quanto ao setor ficou evidenciada na Tabela 2. Tanto em 2011, quanto em 2012 houve maior participação de empresas do setor de serviços. 
Tabela 2. Distribuição de empresas quanto ao setor

\begin{tabular}{ccccc}
\hline & Comércio & Indústria & Serviços & Total \\
\hline $\mathbf{2 0 1 1}$ & 13 & 4 & 22 & 39 \\
$\mathbf{2 0 1 2}$ & 12 & 4 & 24 & 40 \\
\hline
\end{tabular}

Apesar da representatividade do setor de serviços, foi o comércio quem mais empregou entre 2009 e 2011, conforme ilustra a Figura 1. Ao longo dos três exercícios, o setor somou 27.468 postos de emprego, $48 \%$ do total.

Figura 1. Empregabilidade por setor entre 2009 e 2011

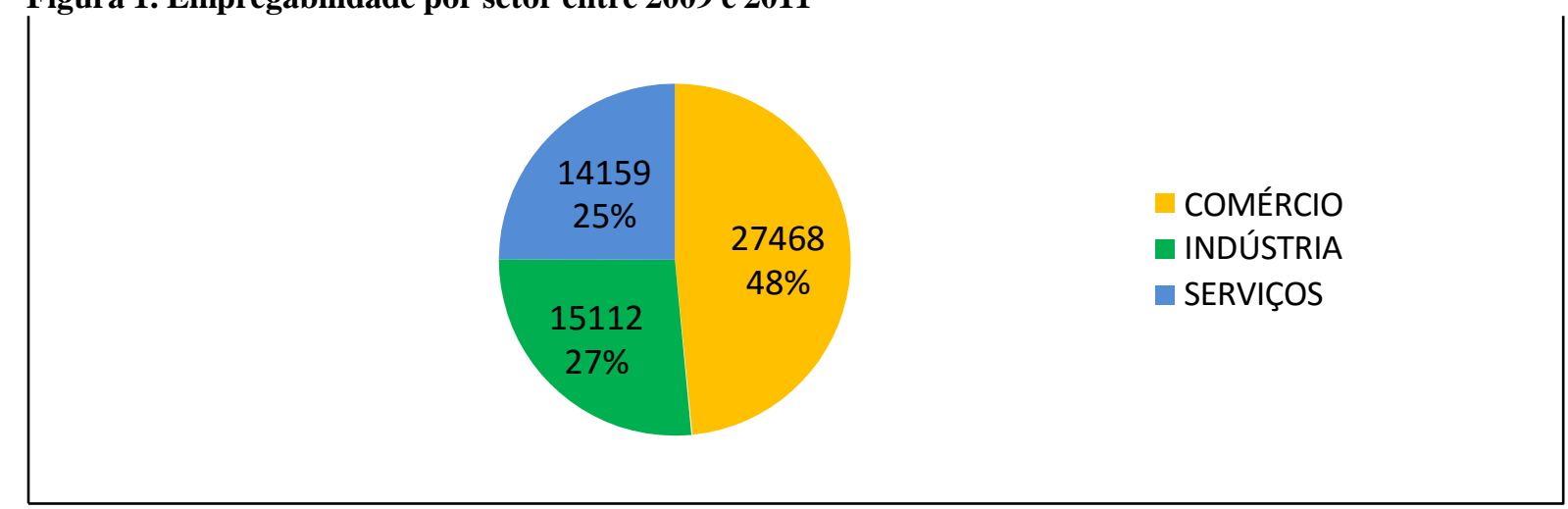

Outro dado analisado foi o número de empregos gerados. A Figura 2 ilustra que no período entre 2009 e 2011 houve geração de 1.883 novos empregos. Não foi possível identificar através dos balanços sociais divulgados, a distribuição quanto à raça, sexo e faixa etária devido à ausência desses dados em $80 \%$ dos relatórios.

Figura 2. Evolução do emprego entre 2009 e 2011

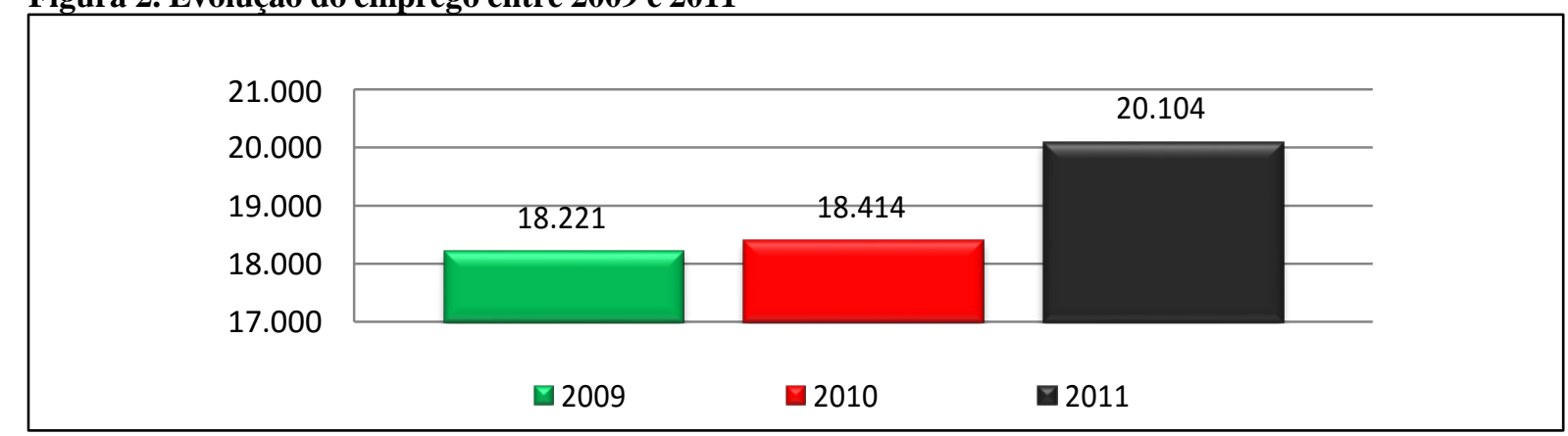

Em seguida, foi elaborado um ranking dos indicadores internos e externos mais divulgados. A Tabela 3 lista todos os indicadores relacionados ao ambiente interno que foram divulgados e a quantidade de empresas que os divulgou. 
Tabela 3. Ambiente Interno - Quantidade de indicadores divulgados

\begin{tabular}{lcc}
\hline Indicadores & $\mathbf{2 0 1 1}$ & $\mathbf{2 0 1 2}$ \\
\hline Alimentação & 35 & 37 \\
Capacitação e Desenvolvimento Profissional & 32 & 31 \\
Creche ou Auxílio Creche & 5 & 5 \\
Educação e Cultura & 20 & 19 \\
Participação nos Lucros e Resultados & 16 & 15 \\
Previdência Privada & 6 & 8 \\
Saúde & 26 & 25 \\
Segurança e Medicina no Trabalho & 29 & 32 \\
Transporte & 2 & 1 \\
Bolsa/Estágio & 1 & 0 \\
Moradia & 1 & 1 \\
Outros & 1 & 4 \\
\hline
\end{tabular}

Os indicadores Alimentação, Capacitação e Desenvolvimento, Educação e Cultura, Participação nos Lucros e Resultados, Saúde, Segurança e Medicina do Trabalho foram os mais divulgados nas duas edições e por isso foram alvo das comparações quanto ao investimento, conforme Tabela 4.

Tabela 4. Evolução dos investimentos - Ambiente Interno

\begin{tabular}{|c|c|c|c|c|}
\hline$(\mathbf{R} \$ \times 1.000)$ & 2009 & 2010 & 2011 & Totais \\
\hline Alimentação & 31.724 & 31.064 & 70.138 & 132.925 \\
\hline Capacitação e Desenvolvimento Profissional & 5.303 & 4.332 & 4.836 & 14.470 \\
\hline Educação e Cultura & 1.483 & 1.741 & 1.391 & 4.615 \\
\hline Participação nos Lucros e Resultados & 31.826 & 31.800 & 58.877 & 122.503 \\
\hline Saúde & 10.184 & 11.689 & 13.245 & 35.118 \\
\hline Segurança e Medicina no Trabalho & 6.631 & 7.349 & 13.890 & 27.870 \\
\hline Totais & 87.151 & 87.975 & 162.376 & 337.502 \\
\hline
\end{tabular}

O investimento no ambiente interno foi crescente e em 2011 representava praticamente o dobro do que foi investido em 2009. Outro dado que pode ser extraído da tabela diz respeito à prioridade das entidades no ambiente interno: Investiu-se prioritariamente em alimentação. Tal fato é reflexo de benefícios fiscais concedidos pela legislação brasileira, como por exemplo o Programa de Alimentação do Trabalhador (PAT), instituído pela Lei $\mathrm{n}^{\circ}$. 6.321, de 14 de abril de 1976. O PAT permite que pessoas jurídicas tributadas com base no lucro real façam a dedução do Imposto de Renda devido do valor correspondente à aplicação da alíquota sobre a soma das despesas de custeio. 
Também foi elaborado um ranking dos indicadores do ambiente externo, de forma a verificar se através dos dados divulgados seria possível acompanhar a evolução dos investimentos. Os dados foram inseridos na Tabela 5.

Tabela 5. Ambiente Externo - Quantidade de indicadores divulgados

\begin{tabular}{lcc}
\hline Indicadores & $\mathbf{2 0 1 1}$ & $\mathbf{2 0 1 2}$ \\
\hline Combate à fome & 6 & 5 \\
Saúde e Saneamento & 14 & 13 \\
Cultura & 19 & 19 \\
Educação & 16 & 15 \\
Esporte e Lazer & 16 & 13 \\
Outros & 4 & 3 \\
Meio Ambiente & 20 & 22 \\
\hline
\end{tabular}

Conforme o ranking da Tabela 5, somente 4 dos 7 indicadores foram amplamente divulgados pelas entidades e por isso foram alvos das análises. A Tabela 6 demonstra que os investimentos também foram crescentes.

Tabela 6. Evolução dos investimentos - Ambiente Externo

\begin{tabular}{|c|c|c|c|c|c|}
\hline Indicadores & $(\mathbf{R} \$ \times 1.000)$ & 2009 & 2010 & 2011 & Totais \\
\hline Cultura & & 9.083 & 9.508 & 10.237 & 28.827 \\
\hline Educação & & 4.736 & 4.785 & 109.940 & 119.460 \\
\hline Esporte e Lazer & & 1.657 & 1.347 & 1.332 & 4.336 \\
\hline Meio Ambiente & & 39.225 & 45.053 & 67.280 & 151.558 \\
\hline Totais & & 54.700 & 60.693 & 188.788 & 304.181 \\
\hline
\end{tabular}

Os valores destinados ao meio ambiente representaram 49,8\% do total investido ao longo dos três exercícios pesquisados, acompanhados da educação que representou $39,3 \%$ do total. Vale ressaltar que o investimento em educação foi 23 vezes maior em 2011 quando comparado a 2009.

Apesar da evolução dos investimentos nos ambientes interno e externo, bem como em meio ambiente, a participação ainda é pequena quando comparada à receita líquida divulgada pelas empresas, conforme disposto na Tabela 7.

Tabela 7. Comparacão entre a receita líquida e os indicadores socioambientais

\begin{tabular}{|c|c|c|c|c|c|c|c|}
\hline & \multirow{2}{*}{$\begin{array}{l}\text { Receita } \\
\text { (xíquxidavov) }\end{array}$} & \multicolumn{2}{|c|}{$\begin{array}{r}\text { Ambiente Interno } \\
\% \text { da }\end{array}$} & \multicolumn{2}{|c|}{ Ambiente externo } & \multicolumn{2}{|c|}{ Meio Ambiente } \\
\hline & & Valor & $\mathbf{R L}$ & Valor & \% da RL & Valor & $\%$ da RL \\
\hline 2009 & 623.963 .347 & 67.574 & $1 \%$ & 13.214 & $0,2 \%$ & 23.302 & $0,4 \%$ \\
\hline 2010 & 736.529 .194 & 69.945 & $1 \%$ & 15.648 & $0,2 \%$ & 26.721 & $0,4 \%$ \\
\hline 2011 & 845.367 .000 & 141.969 & $2 \%$ & 19.778 & $0,2 \%$ & 49.354 & $0,6 \%$ \\
\hline
\end{tabular}


Conforme o estudo de Bertagnolli et al (2005), a receita líquida está associada aos investimentos internos e externos, com destaque especial aos benefícios oferecidos aos funcionários, ou seja, quanto maior o investimento, maior será a receita líquida. De modo geral, o baixo nível de investimentos em relação à receita líquida sugere que a responsabilidade social não passa de mera vitrine, como afirma Bernardo et al (2005;2006).

\section{CONSIDERAÇÕES FINAIS}

Assim como os autores Carvalho e Siqueira (2005) e Pinto e Ribeiro (2004), verificou- se a ausência de padronização não só em relação à estrutura dos balanços sociais, como em relação aos valores divulgados. Tal fato dificultou a comparabilidade das informações dos balanços sociais divulgados. Algumas empresas divulgavam o valor líquido, outras divulgaram múltiplos de 1.000. Além disso, não houve padronização quanto às casas decimais e vários dados foram omitidos o que dificultou a comparação dos dados. Além disso, não foram todas as empresas que contemplaram a DVA.

Na edição de 2011 deveriam constar os dados dos exercícios de 2009 e 2010. Já na edição de 2012, deveriam constar os mesmos dados do exercício de 2010 acrescidos do exercício de 2011, no entanto, alguns balanços apresentavam saldos diferentes com relação ao exercício de 2010, o que coloca em pauta a autenticidade dos balanços e os critérios analisados para concessão do Certificado de Responsabilidade Social.

Em síntese, os objetivos foram alcançados ao responder as questões propostas. Como sugestão de pesquisa, indica-se a inclusão da DVA como critério para obtenção do Certificado de Responsabilidade Social de Mato Grosso, tamanha sua importância e riqueza de informações.

\section{REFERÊNCIAS}

ALBERTON, L.; CARVALHO, F.N.; CRISPIN, G.H. Evidenciação da Responsabilidade Social/Ambiental na Perspectiva de um novo contexto empresarial. $4^{\circ}$ Congresso USP Controladoria e Contabilidade, São Paulo, 2004. Disponível em: $<\mathrm{http} / / /$ www.congressousp.fipecafi.org/artigos42004/cod_trabalho=151>. Acesso em $15 / 05 / 2013$. 
BAGGENTOSS, S.; DONADONE, J. A difusão da responsabilidade social: enfoque no certificado de responsabilidade social de Mato Grosso. Sinop: Unemat, 2009. Disponível em: <http://www.teoriaepesquisa.ufscar.br/index.php/tp/article/view/212/159>. Acesso em $15 / 05 / 2013$.

BERNARDO, D. C. R.; PEREIRA, N. C.; SALAZAR, G. T.; ANTONIALLI, L.M.. Balanço

social não é Vitrine? Um Estudo dos Demonstrativos Sociais das Companhias de Capital Aberto no Brasil. Lavras: UFLA, 2005. Disponível em:

<http://www.aedb.br/seget/artigos06/693_RSE\%20Bernardo,\%20D.\%20C.\%20R..pdf> Acesso em 15/05/2013.

BERNARDO, D. C. R.; PESSANHA, G. R. G.; SILVA, S. S.; AVILA, R. C. Investimentos em responsabilidade social empresarial criam valor para as empresas? Um estudo das companhias de capital aberto no Brasil. In: SEMINÁRIOS DE ADMINISTRAÇÃO, 9, 2006, São Paulo. Anais do IX SEMEAd. São Paulo: FEA/USP, 2006, 1 CD.

BERTAGNOLLI, D. D. O.; OTT, E.; DAMACENA, C. Estudo sobre a Influência dos Investimentos Sociais e Ambientais no Desempenho Econômico das Empresas. CONGRESSO USP DE CONTROLADORIA E CONTABILIDADE. São Paulo: FEA/USP, 2006. $1 \mathrm{CD}$

CARVALHO, F. M.; SIQUEIRA, J. M. DE. Os indicadores ambientais nas normas de Balanço Social. CONTABILIDADE AMBIENTAL E RELATÓRIOS SOCIAIS. São Paulo, Atlas, 2009.

DAVID, A. R. de. Balanço social: uma análise das informações evidenciadas pelas empresas. IX Convenção de Contabilidade do Rio Grande do Sul, 2003. Disponível em: $<$ http://ccontabeis.com.br/conv/t30.pdf>. Acesso em 15/05/2013.

GIL, A. C. Como elaborar projetos de pesquisa. 4. ed. São Paulo: Atlas, 2002.

INSTITUTO ETHOS. Indicadores ethos de responsabilidade social. Disponível em: <www.ethos.org.br>. Acesso em 15/05/2013.

IBASE - Instituto brasileiro de análises sociais e econômicas. Disponível em: <www.ibase.org.br>. Acesso em 15/05/2013.

MARION, J. C. Contabilidade Empresarial. 11. ed. São Paulo: Atlas, 2005.

MACEDO, M. A. S.; SOUSA, A. C.; SOUSA, A. C. C. Desempenho de empresas socialmente responsáveis: uma análise por índices contábil-financeiros. Revista Produção Online, Edição especial/dez. de 2007.

MACHADO, M. A. V.; MACHADO, M. R. Responsabilidade Social Impacta o Desempenho Financeiro das Empresas? IX Congresso USP de Controladoria e Contabilidade, São Paulo, 2009.

MATO GROSSO. Lei n ${ }^{\circ} 7.687$, de 25 de junho de 2002. Cria o Certificado de Responsabilidade Social no Estado de Mato Grosso e dá outras providências. Disponível 
em:<http://www.al.mt.gov.br/v2008/Raiz\%20Estrutura/responsabilidadesocial/ >. Diversos acessos: março/2008 a julho/2009.

PINTO; A.L.; RIBEIRO, M.S. Balanço social: avaliação de informações fornecidas por empresas industriais situadas no estado de Santa Catarina. Rev. contab. finanç. vol.15 no.36 São Paulo Set./Dez. 2004.

RIBEIRO, M. A.; TORRES, A. L.; ROCHA, M. A. Manual Para Elaboração e Apresentação de Monografias. Tangará da Serra: Unemat, 2006.

RICARTE, J. G. Demonstração do Valor Adicionado. Revista Catarinense da Ciência Contábil, Florianópolis, v.4, n.10, p.49-69, dez.2004/ mar.2005.

SANTOS, A. T. DOS; HABECK, C. E.; ASSUNÇÃO, R. C. O. Balanço social - uma análise da divulgação de informações por empresas de capital aberto selecionadas. Revista Repensando, p. 7.

SANTOS, A.; FREIRE, F.; MALO, F. B. O balanço social no Brasil: gênese, finalidade e implementação como complemento às demonstrações contábeis. $22^{\circ}$ Encontro da ANIPAD, 2007, p.80.

SILVA, A. M. Você Monitora a sua Empresa?. Rio de Janeiro: Marins \& Molnar, 2004.

TEIXEIRA, N. G.. A Ètica no Mundo da Empresa. $1^{\circ}$ ed. São Paulo: Thomson Learning, 1998.

TINOCO, J. E. P.; KRAEMER, M. E. P. Contabilidade e gestão ambiental. São Paulo: Atlas, 2004. 